\title{
THE PROJECT-BASED LEARNING: IMPACT ON LEARNING OF GEOL- OGY BY SYRIAN REFUGEE GRADE 6 STUDENTS
}

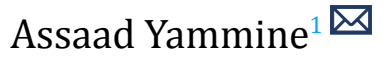 \\ ${ }^{1}$ Faculty of Pedagogy, Lebanese University, Beirut, Lebanon
}

Received 6 May 2021

Accepted 20 May 2021

Published 31 May 2021

Corresponding Author

Assaad Yammine, yammineassaad

@gmail.com

DOI $10.29121 /$

granthaalayah.v9.i5.2021.3952

Funding: This research received no specific grant from any funding agency in the public, commercial, or not-for-profit sectors.

Copyright: (C) 2021 The Author(s). This is an open access article distributed under the terms of the Creative Commons Attribution License, which permits unrestricted use, distribution, and reproduction in any medium, provided the original author and source are credited.

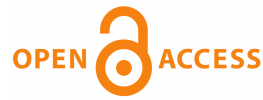

\section{ABSTRACT}

Young Syrian refugees who have experienced the war are in a state of trauma that hinders their normal development, be it physical, emotional, behavioural or even at school level. Geology is, therefore, a difficult field to address for both students and teachers. In order to familiarize primary school students (grade 6) with this theme, we have set up and realized a pedagogical project at the "Janah" educational centre that deals with Syrian refugee students enrolled in public schools in Lebanon. We integrated project-based learning (PBL) into teaching in order to introduce grade 6 students to some basics in geology. Several tests were conducted before and after our intervention. The results show that the PBL develops students' motivation and involves them more in learning situations while starting from their interests and promoting their cognitive engagement. In addition, PBL promotes their autonomy, awakens their sense of responsibility by integrating them into teams where they collaborate and communicate.

Keywords: ProjectBased Learning, Primary School, Motivation

\section{INTRODUCTION}

Young Syrian refugees who experienced the war are in a state of trauma that hinders their normal development, whether physical, emotional, behavioural and cognitive level. All this influences the psychological development of the child and, consequently, his level of learning. The personal and psychosocial responses that each refugee child draws from his memories and experience do not go away when he walks through the door of the school. He brings with him this emotional and social baggage and educators must take this into account Azdouz (2003). As a result, these students find themselves behind school and - when they are re-enrolled in public schools in Lebanon - have to deal with a demotion at a class level. This causes a loss of interest and motivation for any activity and causes a feeling of rejection and failure at home.

Working geology with refugee students is a challenge given the dual complexity of the topic on one hand and the population concerned on the other. Our study will 
try to verify to what extent the integration of the project-based learning (PBL) contributes to the development of motivation and autonomy, as well as to the appropriation of some geology concepts by grade 6 refugee students. This will promote the integration of PBL into the systems and schools that deal with pupils requiring specific support.

\section{METHODOLOGY}

The NGO "Semeurs d'avenir" is part of the IECD (European Institute of Coordination and Development) organization which supports the educational project that supports children and young people who come from vulnerable families. The educational centre Janah associated to "Semeurs d'avenir" welcomes immigrant students who are enrolled in public schools and helps them to overcome the obstacles they face psychologically, socially as well as at the educational level. Ten students of grade 6 class (three boys and seven girls), belonging to the same age group (12-14 years) were invited to work together and conduct research to learn and acquire the concepts, design a final product, the result of their learning and introduce it to others. Data collection was done through knowledge, motivation and autonomy tests.

\section{RESULTS AND DISCUSSION}

\subsection{ANALYSIS OF TEST RESULTS ASSESSING MOTIVATION AND AUTONOMY}

The particularity of our work is in testing the impact of project pedagogy on refugee students with psychological, social and academic difficulties.

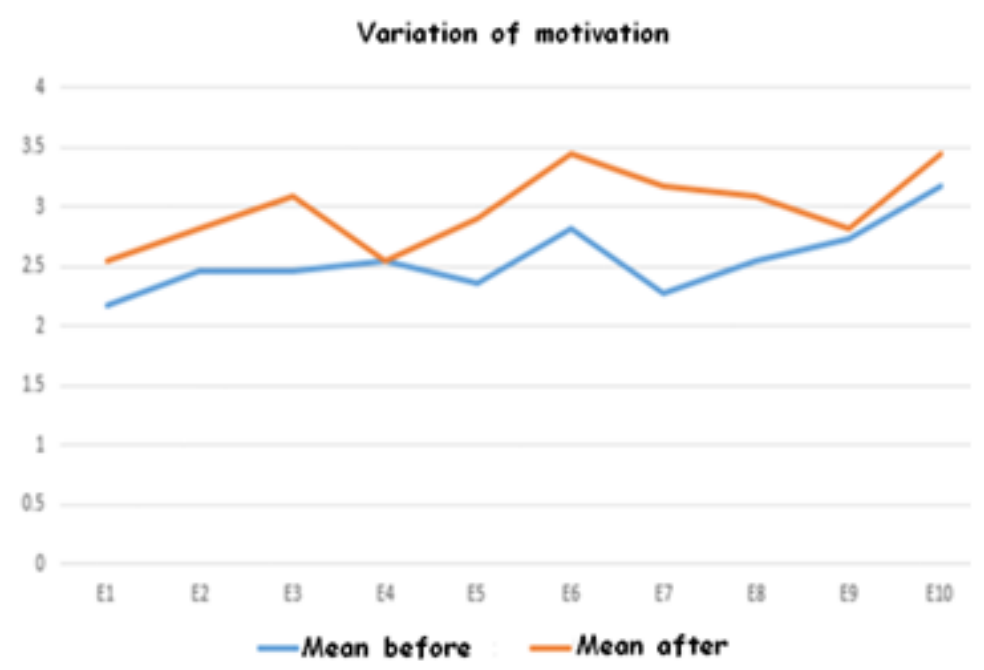

Graph 1: Variation in means of student motivation beforeand after application of PBL. 


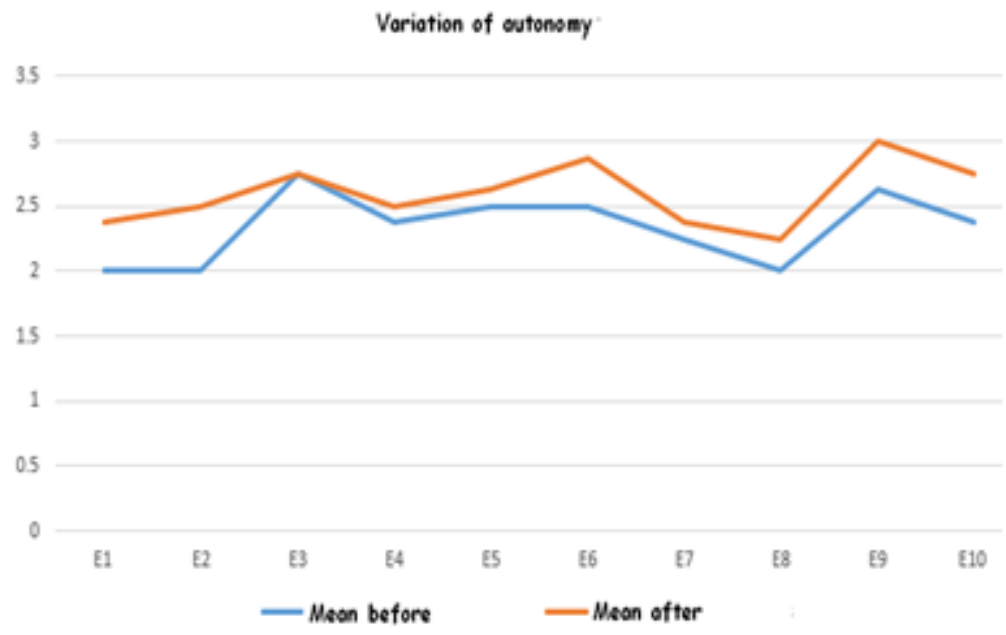

Graph 2: Mean Change in the autonomy of the studentsbefore and after the implementation of PBL.

Graph 1 and Graph 2 show that the average motivation and autonomy of the majority of students has increased after the application of PBL. This increase is not the same for all students.

PBL seems to have a positive impact on the motivation and autonomy of refugee students. This impact seems to be associated with other factors to be defined.

Our results on motivation confirm those of Genest and Pellaton (2012), where student motivation increased after the project was completed.

Talbi et al. (2007) did not notice a development at the level of autonomy, which is inconsistent with the increase of the autonomy level we found.

\subsection{ANALYSIS OF ACHIEVEMENT TEST SCORES}

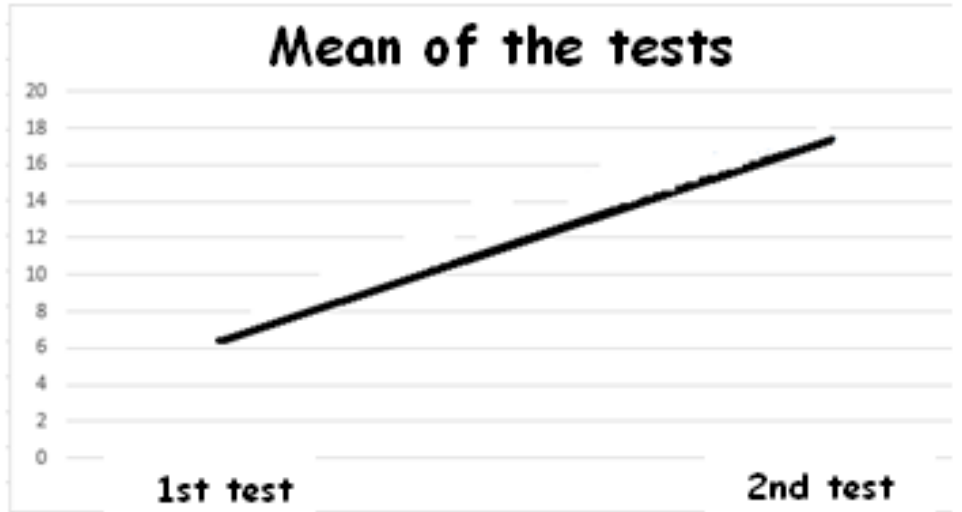

Graph 3: Variation of average marks of students in theachievement tests before and after the application of the PBL. 
Graph 3 shows a variation of the averages of the achievement tests done by the students, before and after the implementation of the project. We observe a significant increase of the average of 6.5 / 20 in the 1st prerequisite test carried out before the application of the project, to reach approximately 17/20 at the 3rd test level, final test carried out at the end of the project for test the notions acquired by the students.

This result shows a clear improvement in knowledge following the implementation of PBL. These results are consistent with those of Lebrun (2002) who claims that PBL allows students to acquire knowledge better.

Despite all the limitations we faced in carrying out our project, we find that PBL develops students' motivation and involves them more in learning situations while starting from their interests and promoting their cognitive engagement. In addition, PBL promotes their autonomy, awakens their sense of responsibility by integrating them into teams where they collaborate and communicate.

\section{REFERENCES}

Azdouz, R. (2003). L'intégration Des Enfants Touchés Par La Guerre Dans Les Ecoles De Montréal. Guide A L'intention Du Personnel Enseignant Et Non Enseignant. In C. D. G. D. L. T. S. D. L. D. Montréal (Ed.), Lintégration Des Enfants Touchés Par La Guerre Dans Les Ecoles De Montréal. Guide A L'intention Du Personnel Enseignant Et Non Enseignant.

Genest, O., \& Pellaton, C. (2012). L'impact De La Pédagogie De Projet Sur La Motivation, Le Sens Et Le Développement Des Compétences Transversales. Haute École Pédagogique De Lausanne. In L. D. L. P. D. P. S. L. Motivation \& L. S. E. L. D. D. C. T. H. École Pédagogique De Lausanne (Eds.), .

Lebrun, M. (2002). Théories Et Méthodes Pédagogiques Pour Enseigner Et Apprendre. Bruxelles. In Théories Et Méthodes Pédagogiques Pour Enseigner Et Apprendre. Bruxelles: De Boeck Université.

Talbi, M., Benichou, E., Kabbaj, M., Et, B. G., \& Abouhanifa, S. (2007). Encadrement Des Projets De Production Des Elèves Du Collège. Le Palimpeste Revue De L'éducation Et De Formation. In Compétence : Encadrement Des Projets De Production Des Elèves Du Collège. Le Palimpeste Revue De L'éducation Et De Formation. Maroc. 